\title{
Robotic External Leak Locator (RELL) leak plume field detection on the International Space Station (ISS)
}

SPACE ENVIRONMENT EFFECTS | External Contamination | Plasma | IR | Acoustics Mission Success • Safety • Reliability

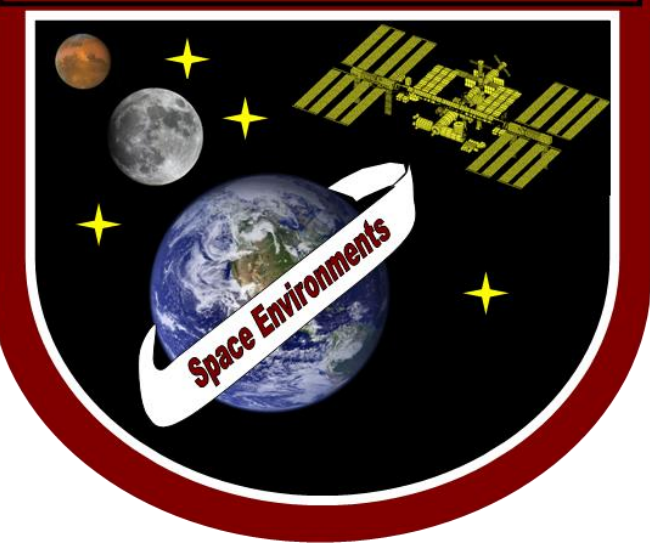

aThe Boeing Company 'NASA Johnson Space Center

c Conceptual Analytics, NASA Goddard Space Flight Center

August 20, 2018
Alexandra M. Deala, Katie L. Foxa, Alvin Y. Huanga, Michael J. Heisera, William A. Hartmana, Ronald R. Mikatariana, Matthew J. Davisa Adam Naids', Timothy A. Bond ${ }^{b}$, Brien Johnson ${ }^{b}$ Dino J. Rossettic 


\section{Background}

$>$ The United States External Active Thermal Control System (EATCS) on the International Space Station (ISS) uses liquid ammonia in closed loops to collect, transport, and reject heat.

$>$ Detection and location of small ammonia leaks (estimated to be $<50 \mathrm{lbm}$ per day) from the EATCS was identified as a risk by the ISS program and the Robotic External Leak Locator (RELL) was commissioned to demonstrate the capability to locate these small leaks.

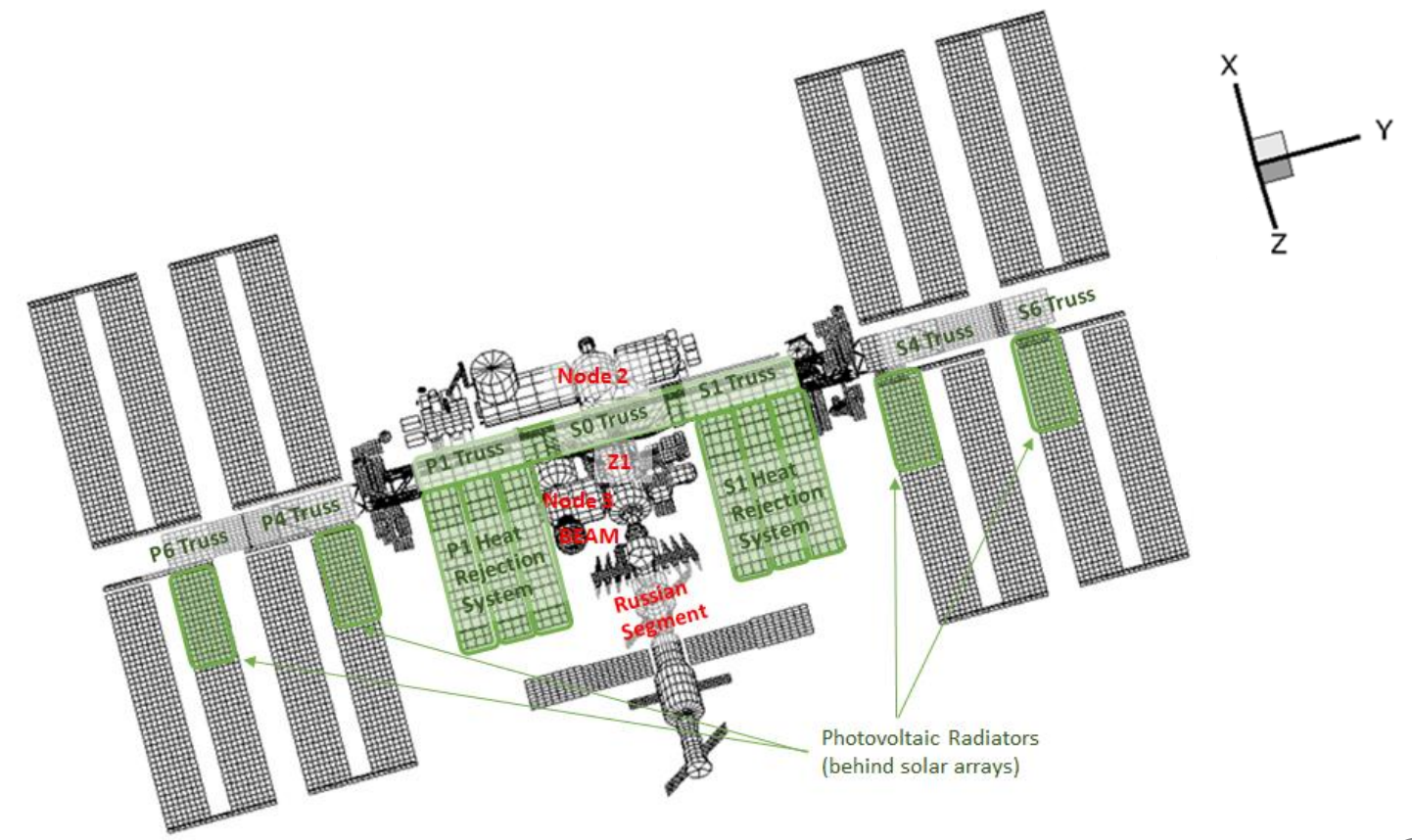

Boeing Space Environments Team 


\section{Robotic External Leak Locator}

> Collaboration between NASA's Goddard Space Flight Center and Johnson Space Center

> Maneuvered with Space Station Remote Manipulator System (SSRMS) and Special Purpose Dexterous Manipulator (SPDM) robotic arms

$>$ PKR 251 lon Gauge: Combination total pressure gauge

$>$ Pirani gauge

$>$ Cold cathode system

$>$ Residual Gas Analyzer - 100

$>$ Quadrupole gas analyzer that measures for a mass range from 1 to 100 ion mass-to-charge ratios

$>$ Heated filament bombards incoming gas with electron creating positive ions.

$>$ The ions are directed toward the quadrupole filter where they are separated by their mass-to-charge ratio.

$>$ A Faraday Cup detector measures current directly and for increased sensitivity, an electron multiplier measures the electron current proportional to ion current.

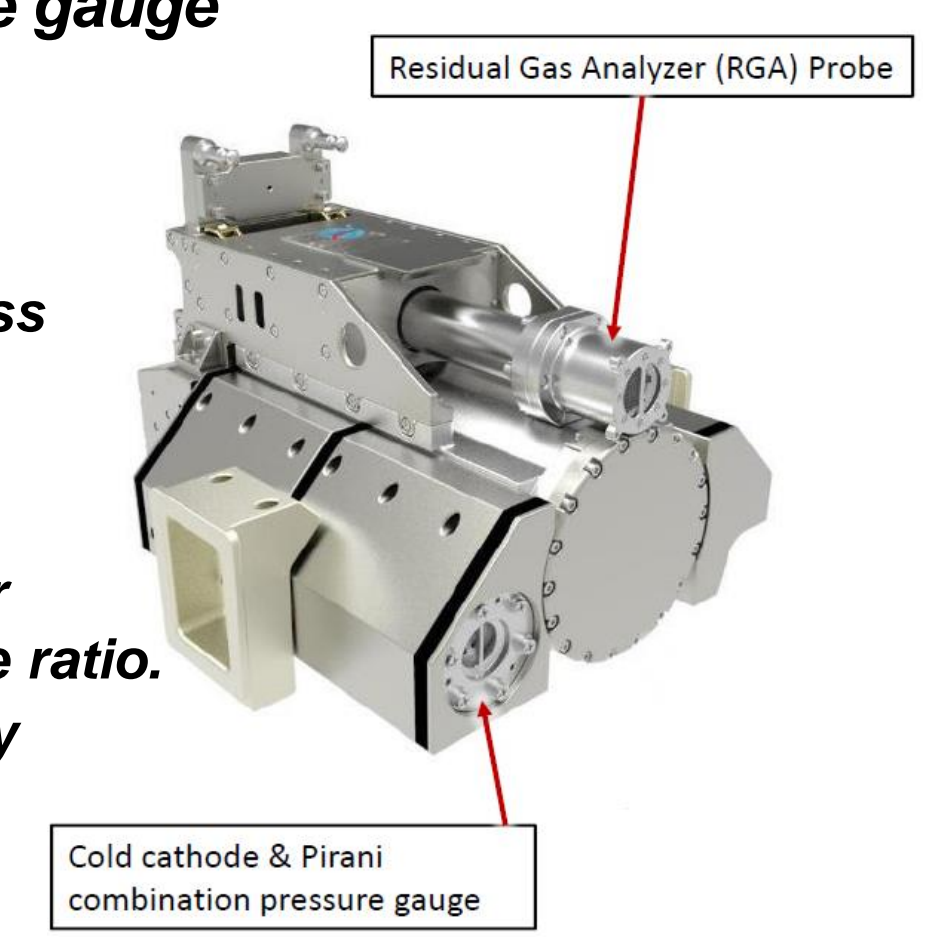




\section{RELL Measurement of Water and Ammonia}

$>$ Use ion mass ratios of 16 to 17 , in additional to total pressure, to distinguish between water and ammonia

$>$ Water: 0.04

$>$ Ammonia: 0.80
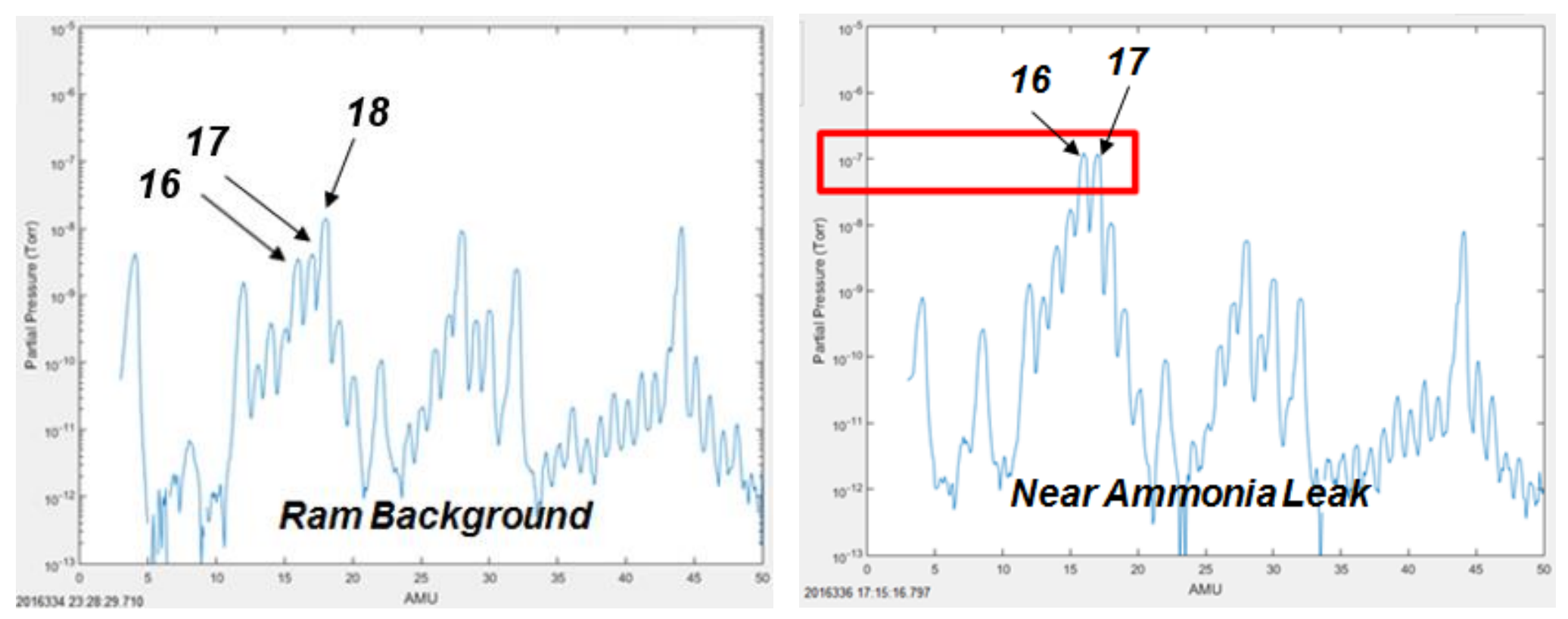


\section{RELL Scanning of RBVMs}

> Six Radiator Beam Valve Modules (RBVMs) on each side of the ISS

$>$ Two per radiator panel

$>$ Etc

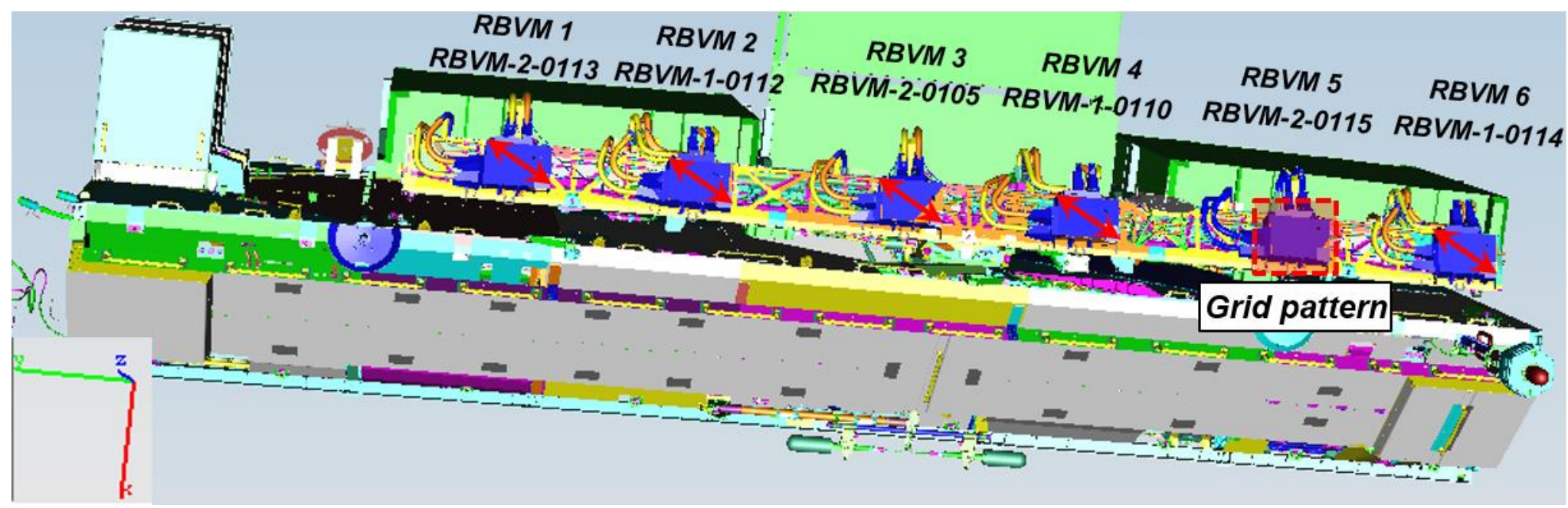




\section{RBVM Scans - Partial Pressure}

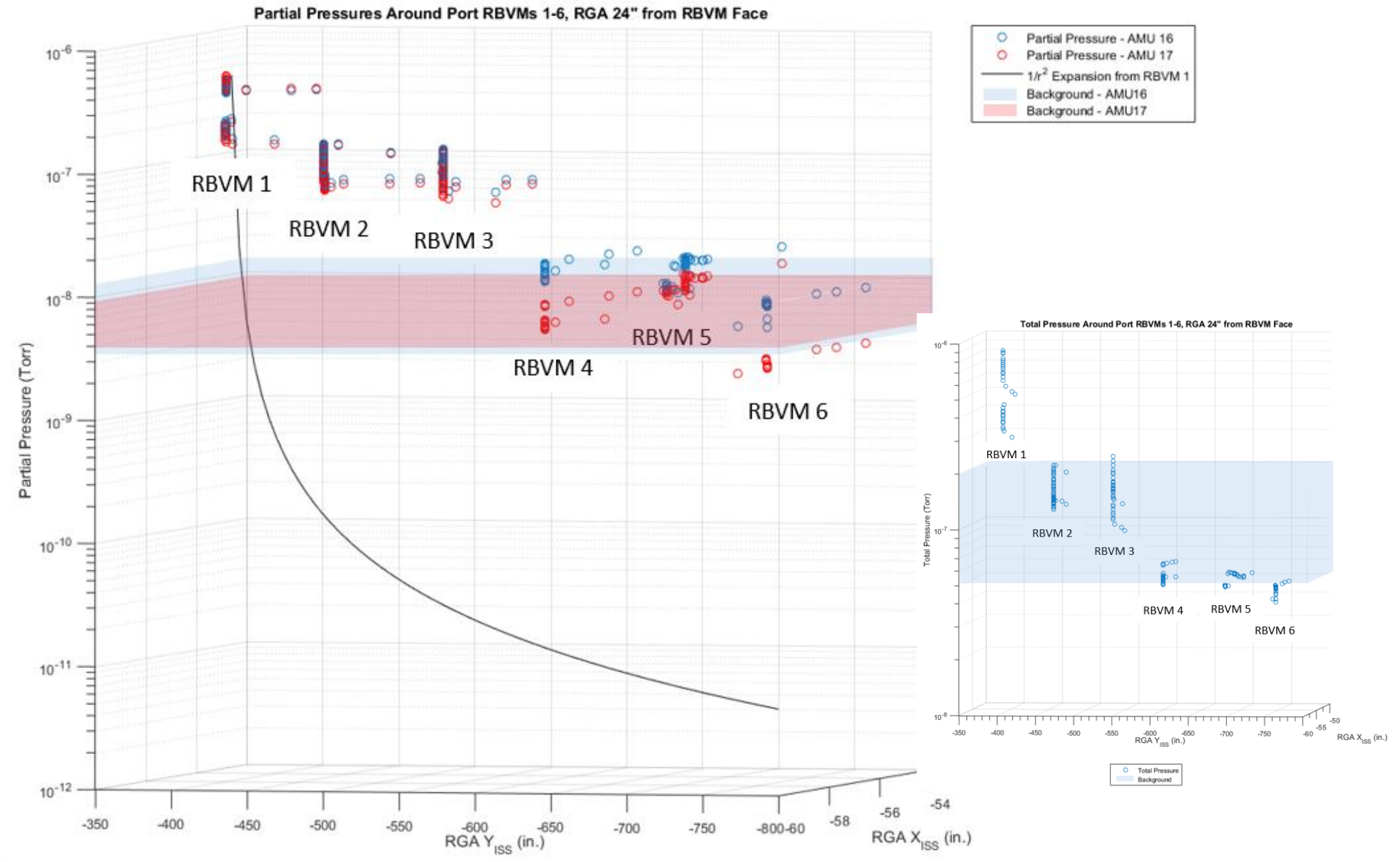




\section{RBVM Scans - Total Pressure}

Total Pressure Around Port RBVMs 1-6, RGA 24" from RBVM Face

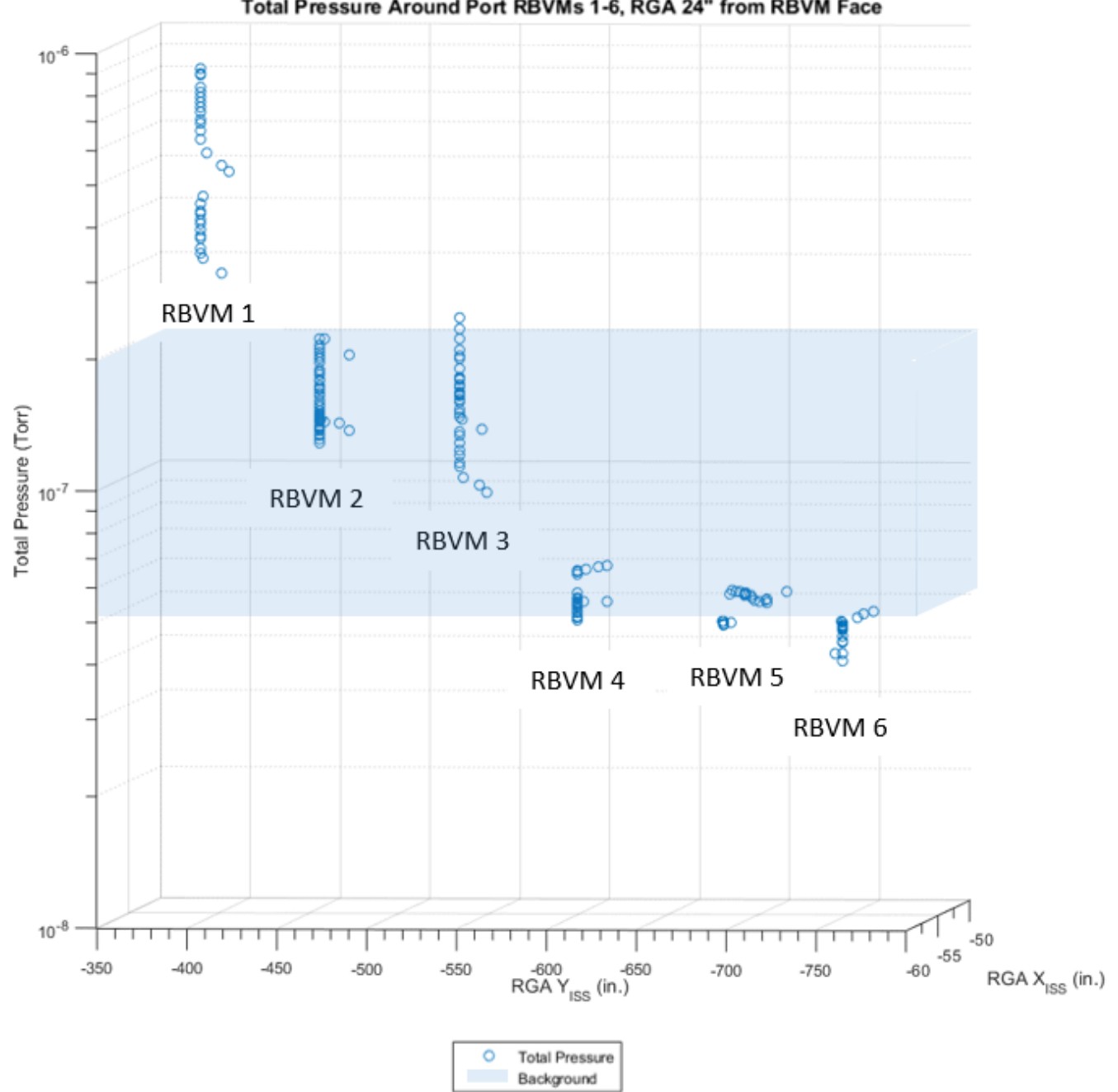

Boeing Space Environments Team

Publically available - NASA EDAA NF1676 TN59109 


\section{Rescan of RBVM 1}

$>$ An additional day of scanning was planned for the end of the onorbit demonstration in December 2016 after reviewing the initial scanning data
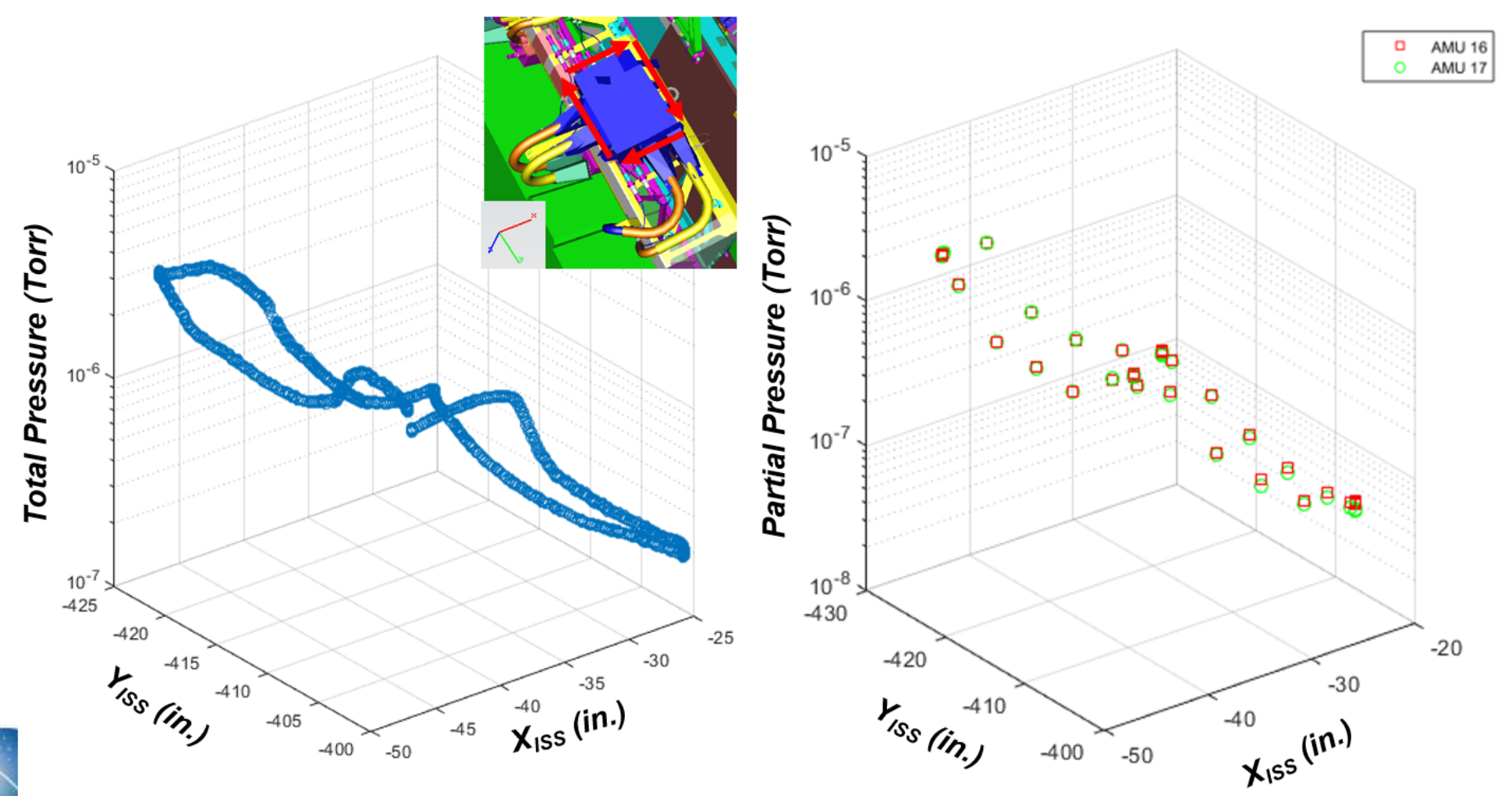


\section{Rescan of RBVM 1}

$>$ An additional day of scanning was planned for the end of the onorbit demonstration in December 2016 after reviewing the initial scanning data

$>$ Pass over RBVM flex hoses and quick disconnects (QDs)
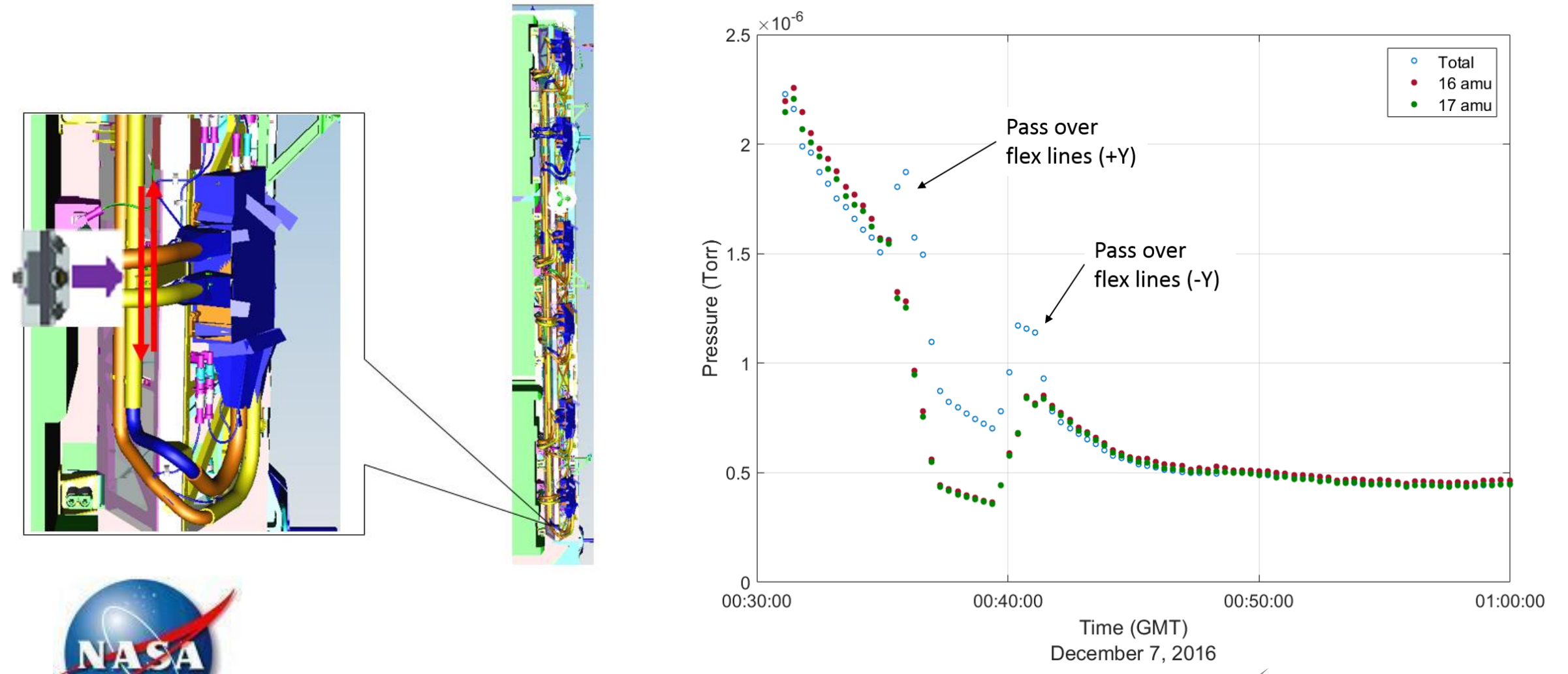


\section{Focused RBVM 1 Inspection}

$>$ RELL approved for external operations in February 2017 after observed EATCS leak rate increased.

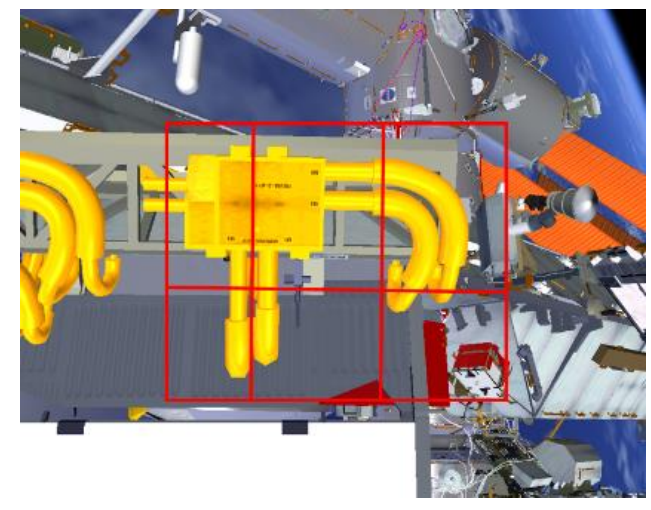

Zenith (-Z) face

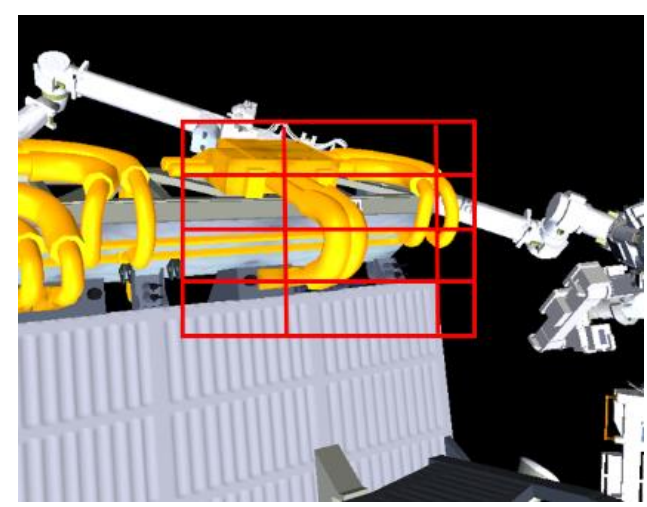

Aft-Port $(-X /-Y)$ face

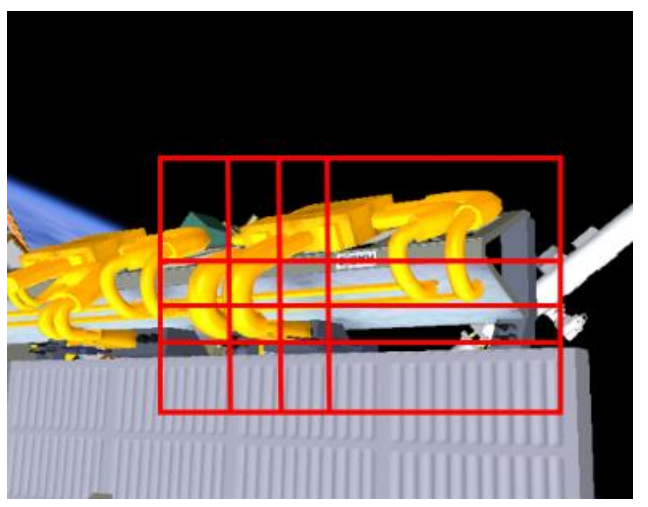

Aft-Starboard $(-X /+Y)$ face

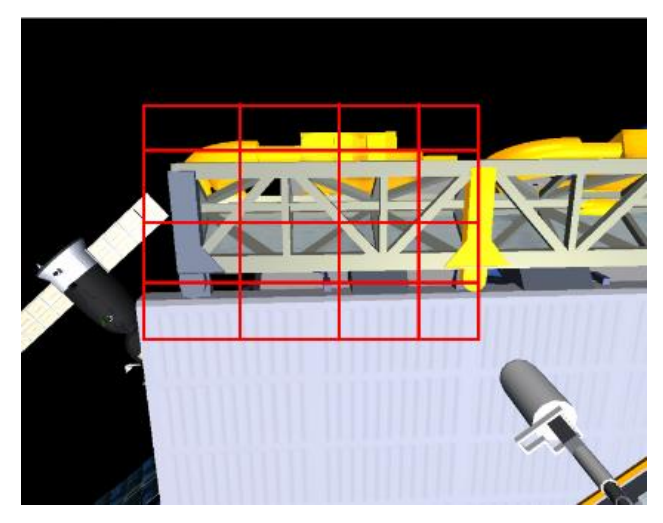

“Back” face 


\section{Focused RBVM 1 Inspection: Zenith (-Z) Face}

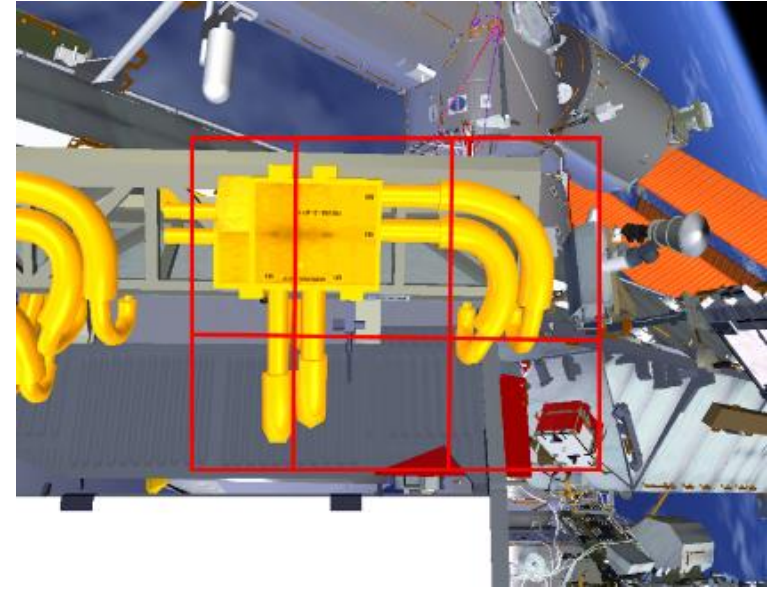

Zenith (-Z) face

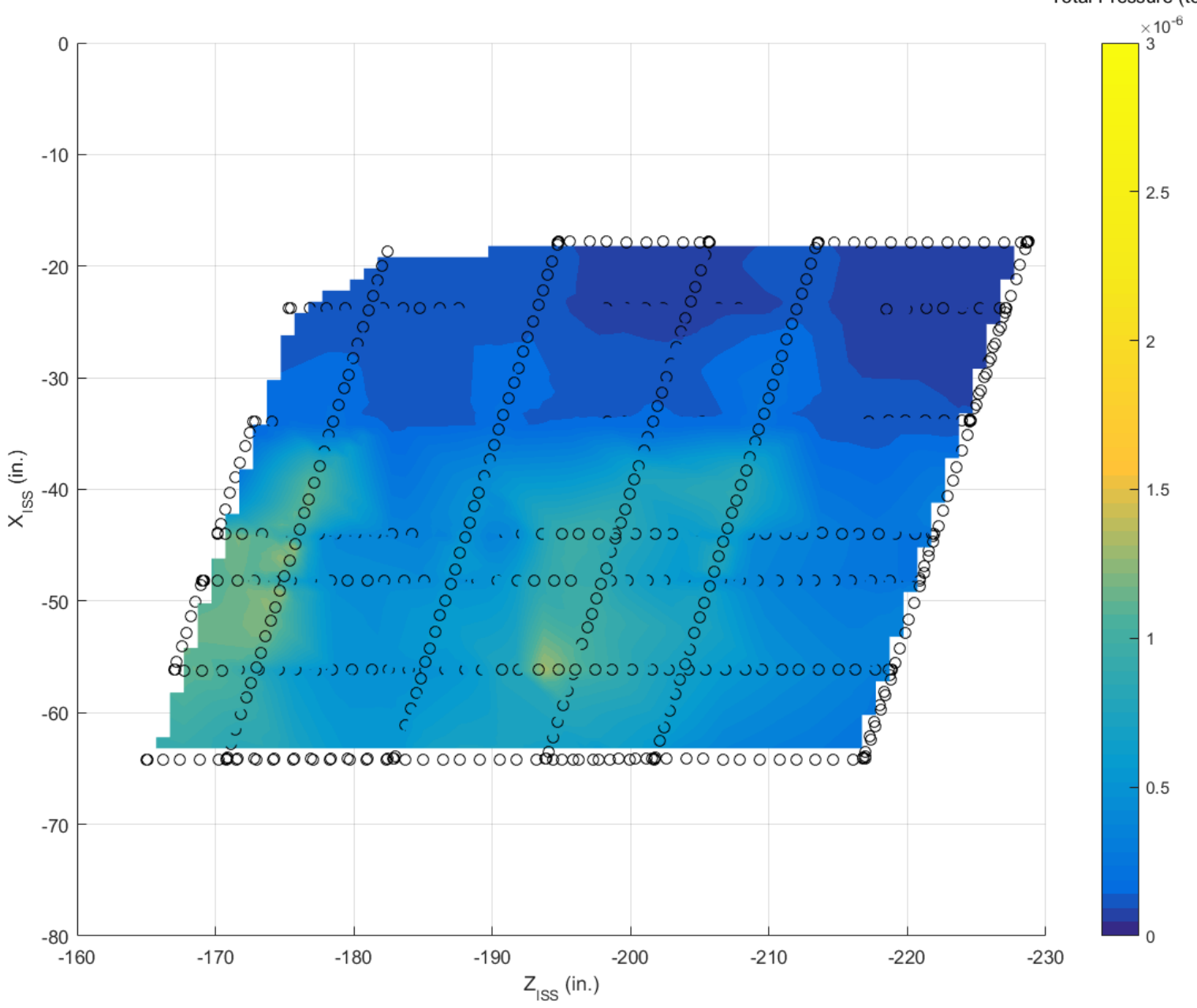




\section{Focused RBVM 1 Inspection: Aft-Starboard $(-X \mid+Y)$ Face}

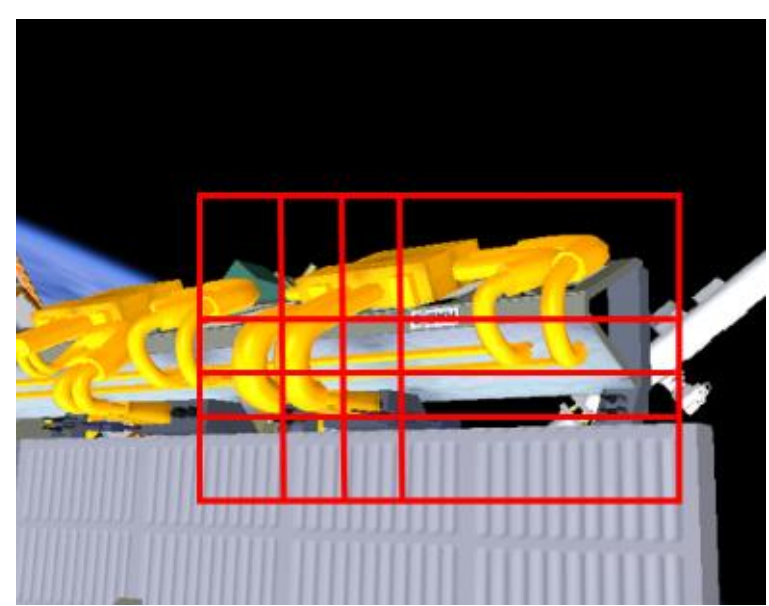

Aft-Starboard $(-X /+Y)$ face

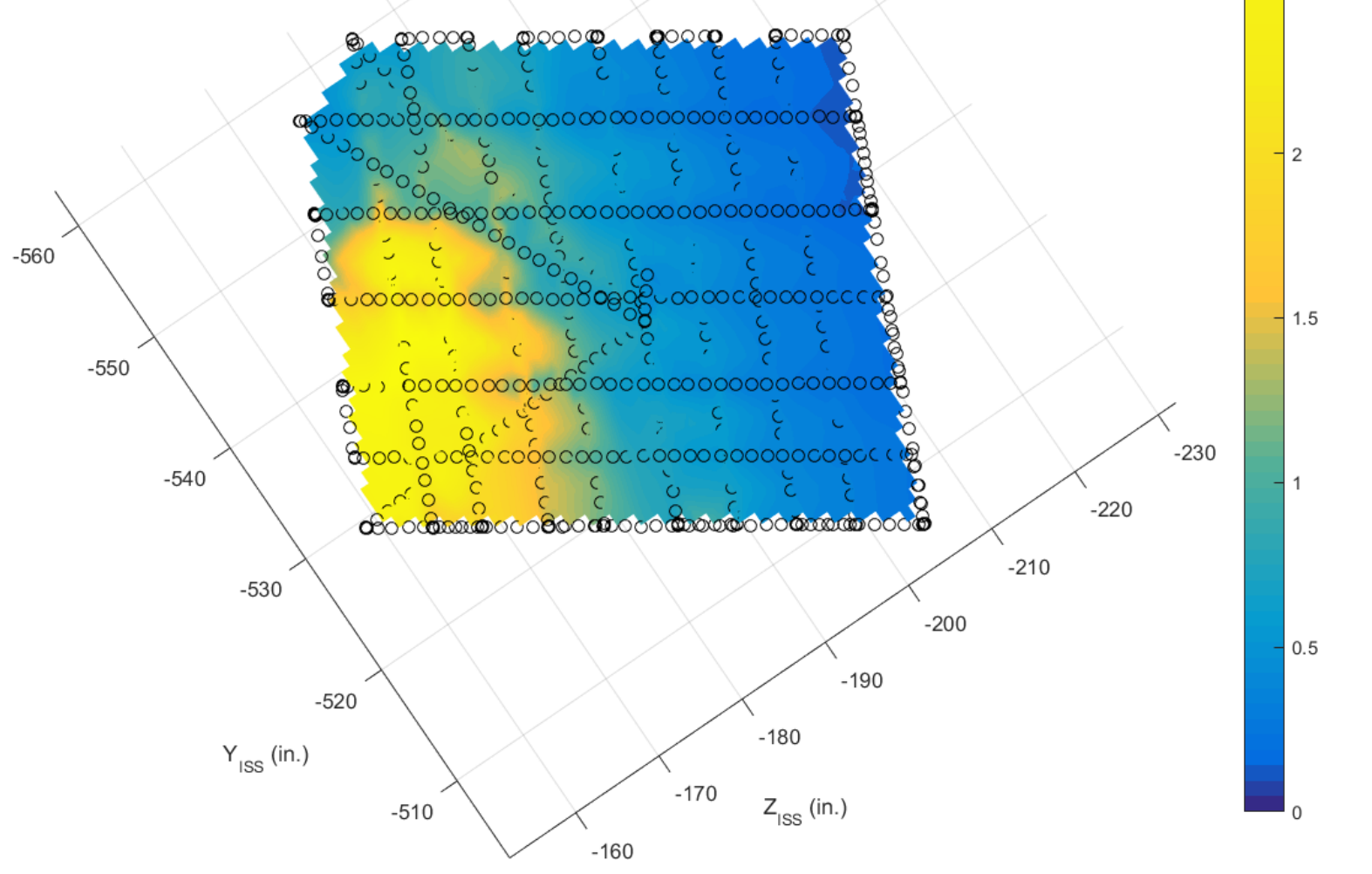




\section{Focused RBVM 1 Inspection: Aft-Starboard $(-X \mid+Y)$ Face}

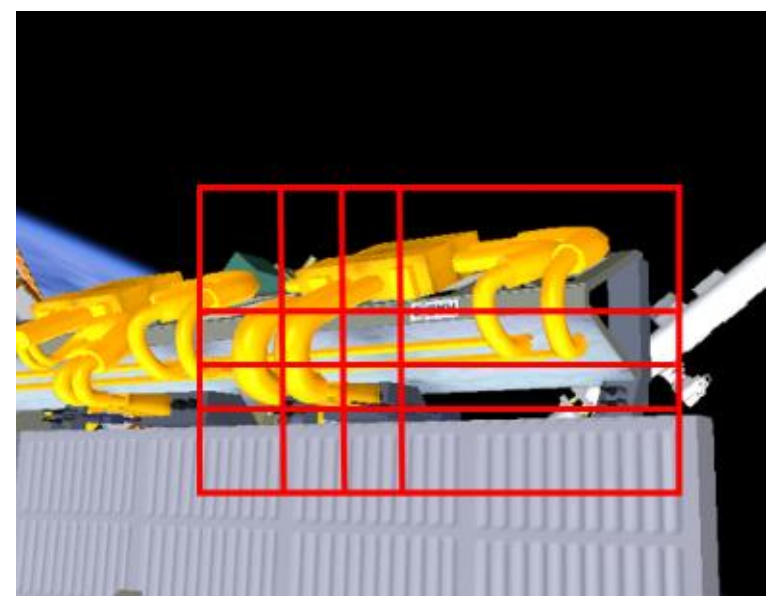

Aft-Starboard $(-X /+Y)$ face

Expanded Scan

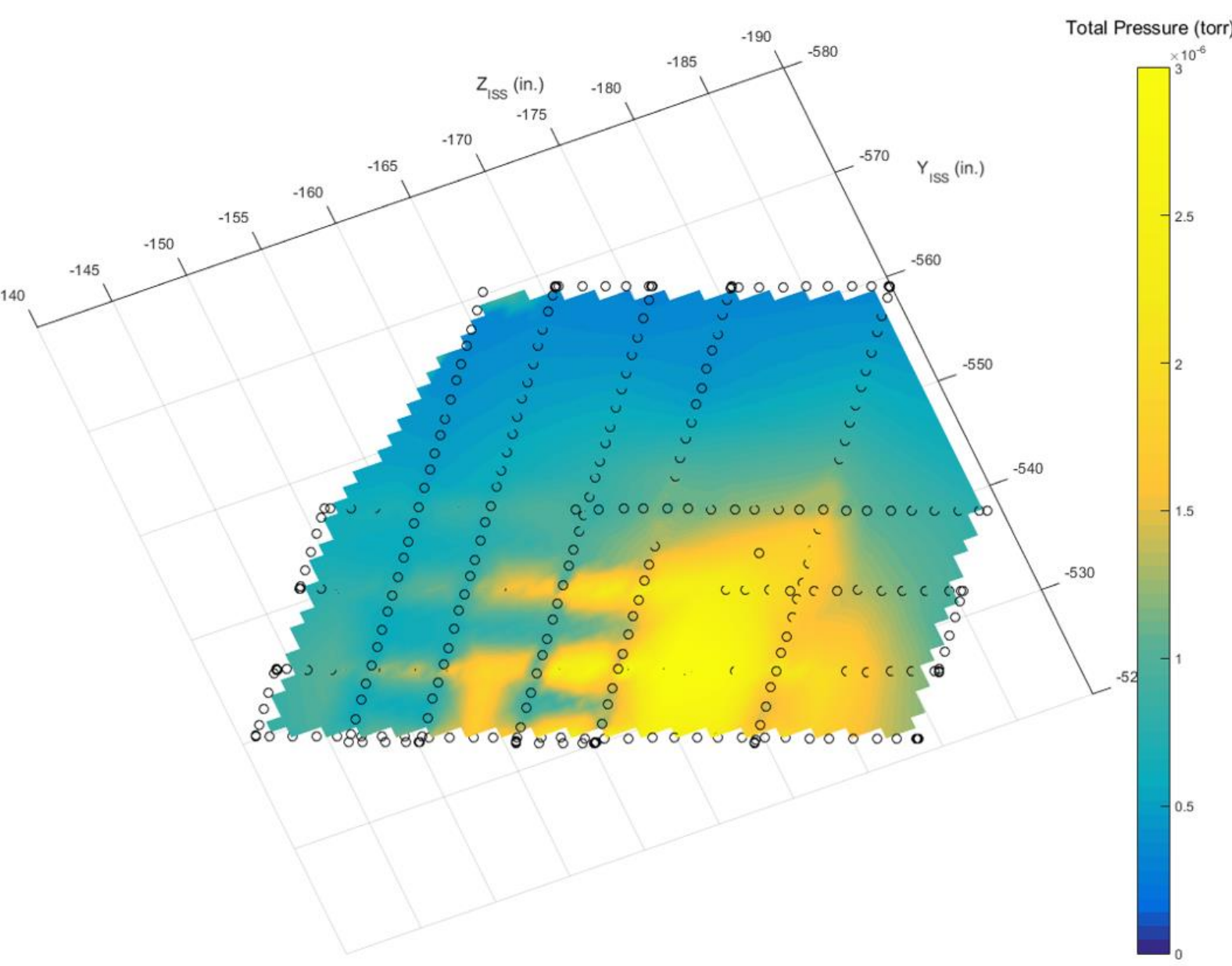

Boeing Space Environments Team Publically available - NASA EDAA NF1676 TN59109 


\section{Focused RBVM 1 Inspection: Aft-Port (-X I -Y) Face}

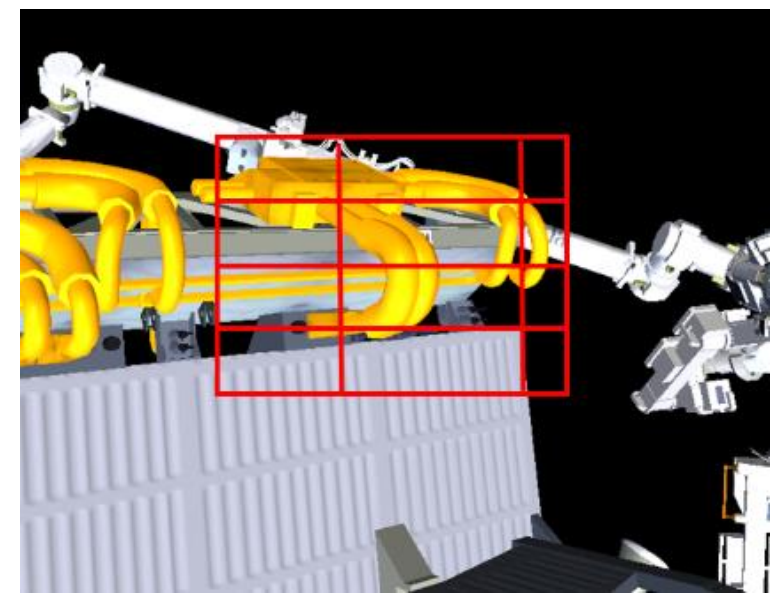

Aft-Port (-X/-Y) face 


\section{Focused RBVM 1 Inspection: Aft-Port (-X I -Y) Face}

Total Pressure

'Horizontal' Direction Scans

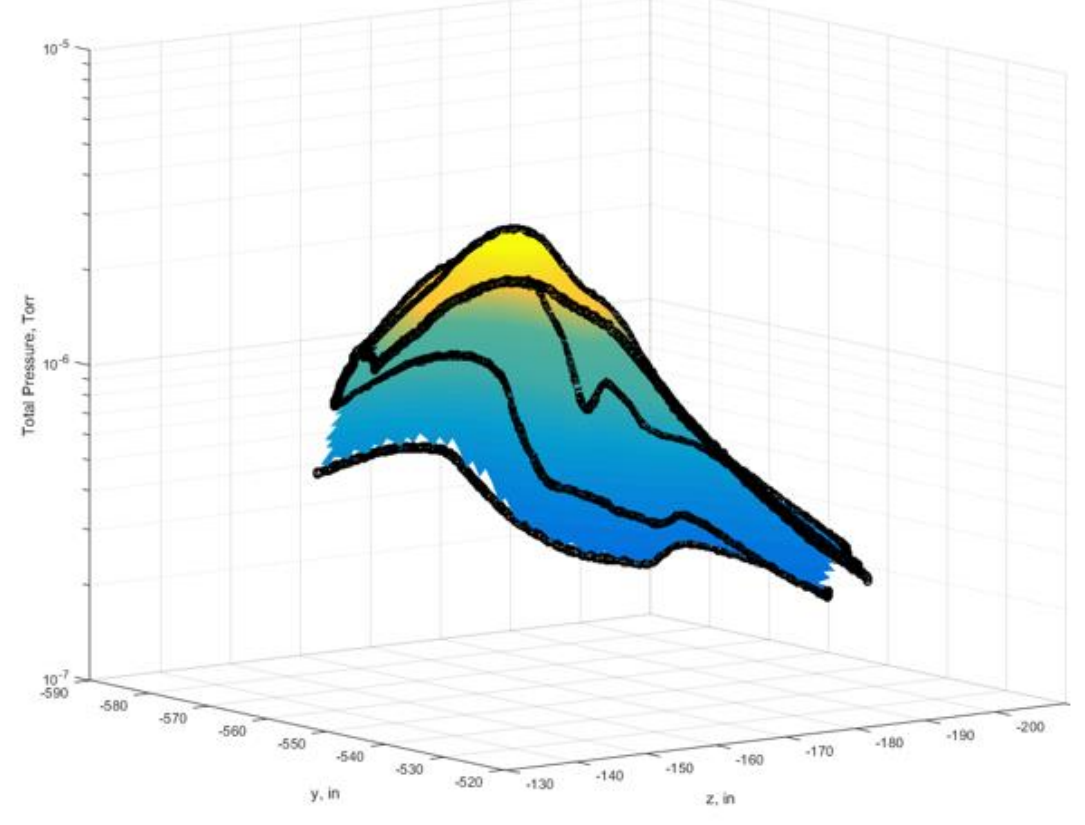

'Vertical' Direction Scans

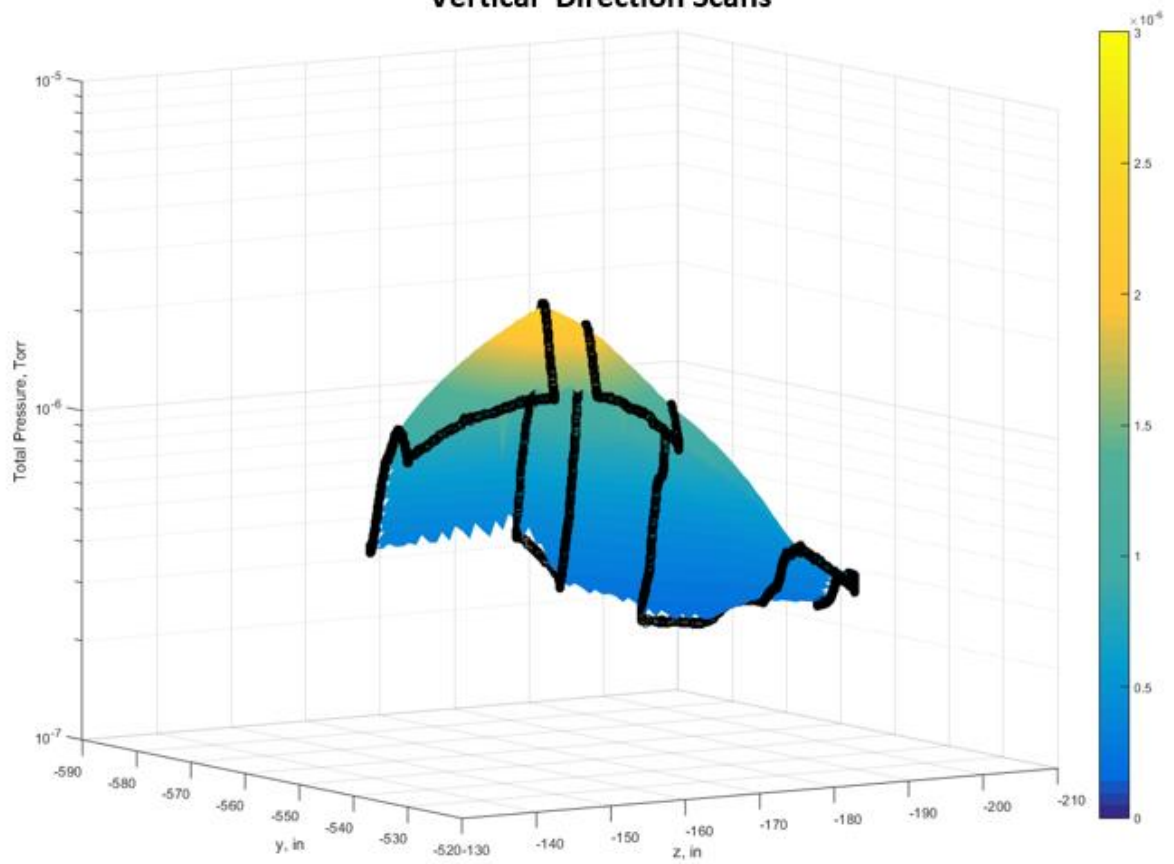




\section{Focused RBVM 1 Inspection: "Back Side"}
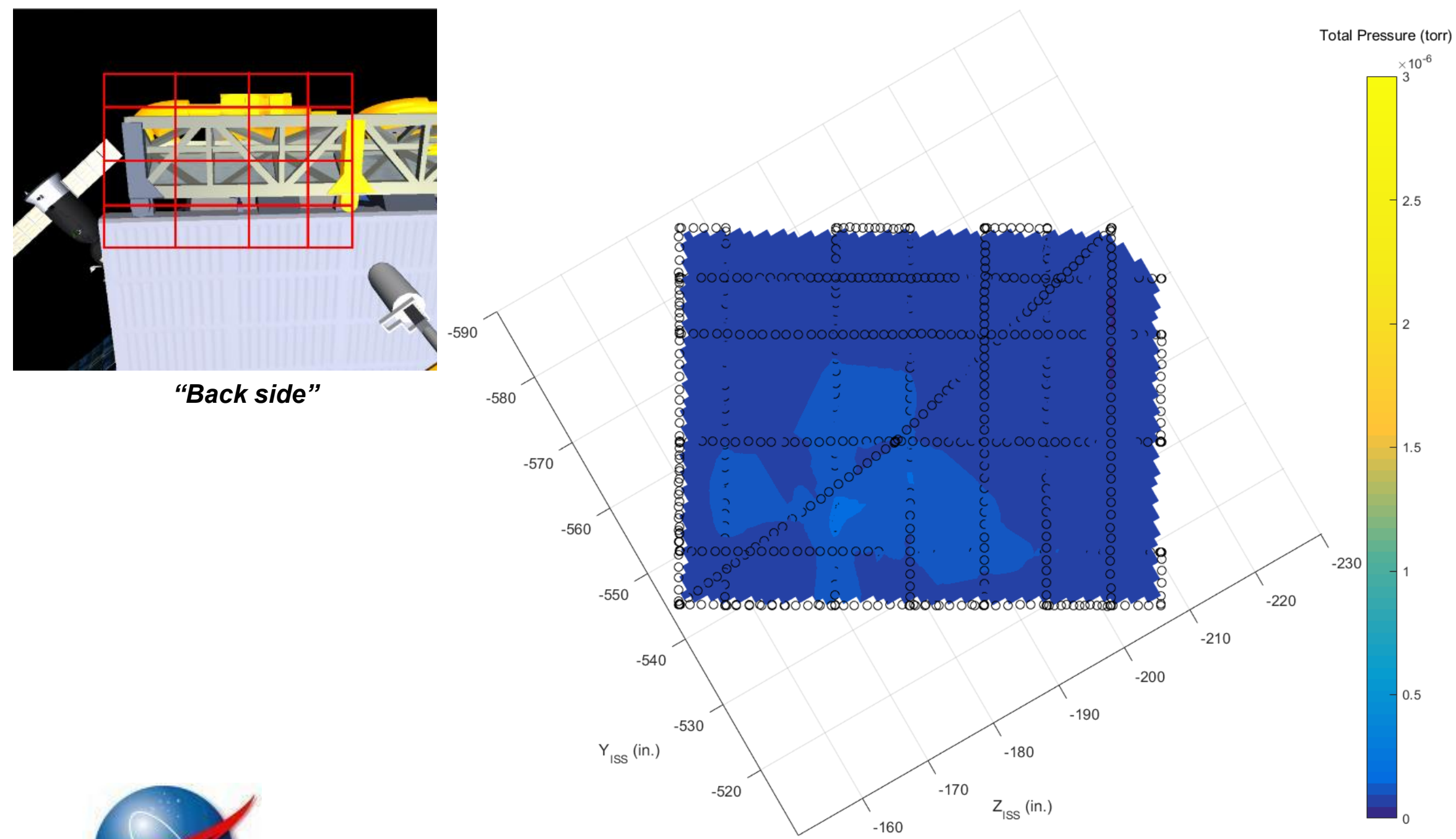


\section{Conclusions}

$>$ RELL was successful in detecting and locating an ammonia leak during the on-orbit demonstration and additional inspection in February 2017.

$>$ Potential leak site inspected by a crew member during an EVA in March 2017 and HD video showed small flakes originating from the coolant lines.

$>$ Coolant lines isolated in April 2017 and subsequent monitoring of system pressures showed the leak had stopped.

$>$ Radiator-side coolant line retrieved by EVA in March 2018 for inspection on the ground.

$>$ Grid scanning technique is effective and repeatable for locating leaks.

$>$ Total pressure measurements using the ion gauge are useful in building contour maps of pressure.

$>$ Need to be combined with RGA partial pressure measurement data to determine what is causing the differences in total pressure. 


\section{Acknowledgements}

$>$ Contributions during the design and verification stages of the Robotic External Leak Locator:

$>$ Jesse A. Buffington

$>$ David Autrey

$>$ Carlos E. Soares

$>$ Matthew J. Roode

$>$ Steven B. Morris

$>$ Michael S. Woronowicz

$>$ Stanford Research Systems for their support during on-orbit operations in November - December 2016 and February 2017:

$>$ Matt Kowit

$>$ Dave Doheny 
$>$ Contact Information

$>$ Alexandra Deal, alexandra.m.deal@gmail.com

>Katie Fox, katie.l.fox@boeing.com

$>$ Questions? 


\section{Back Up}




\section{Background Scanning A: Ram (+X)}

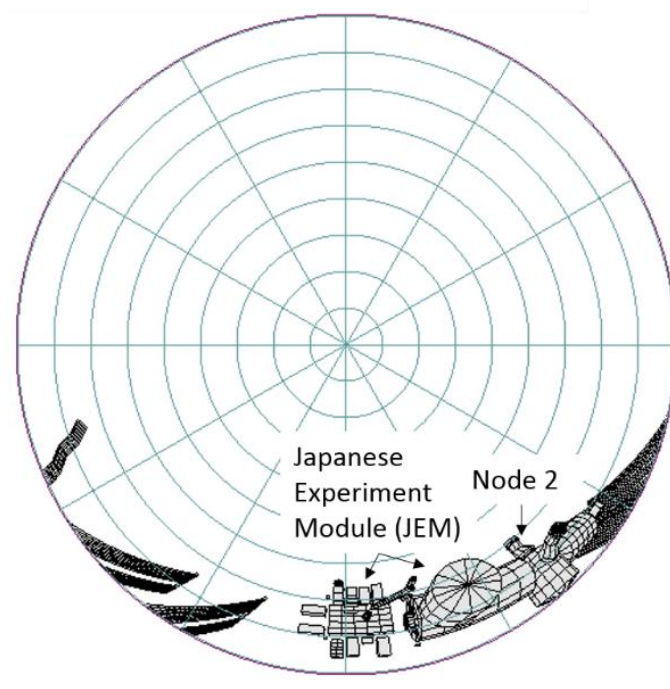

$>$ Sum of RELL RGA partial pressures includes AMU 3 to 50

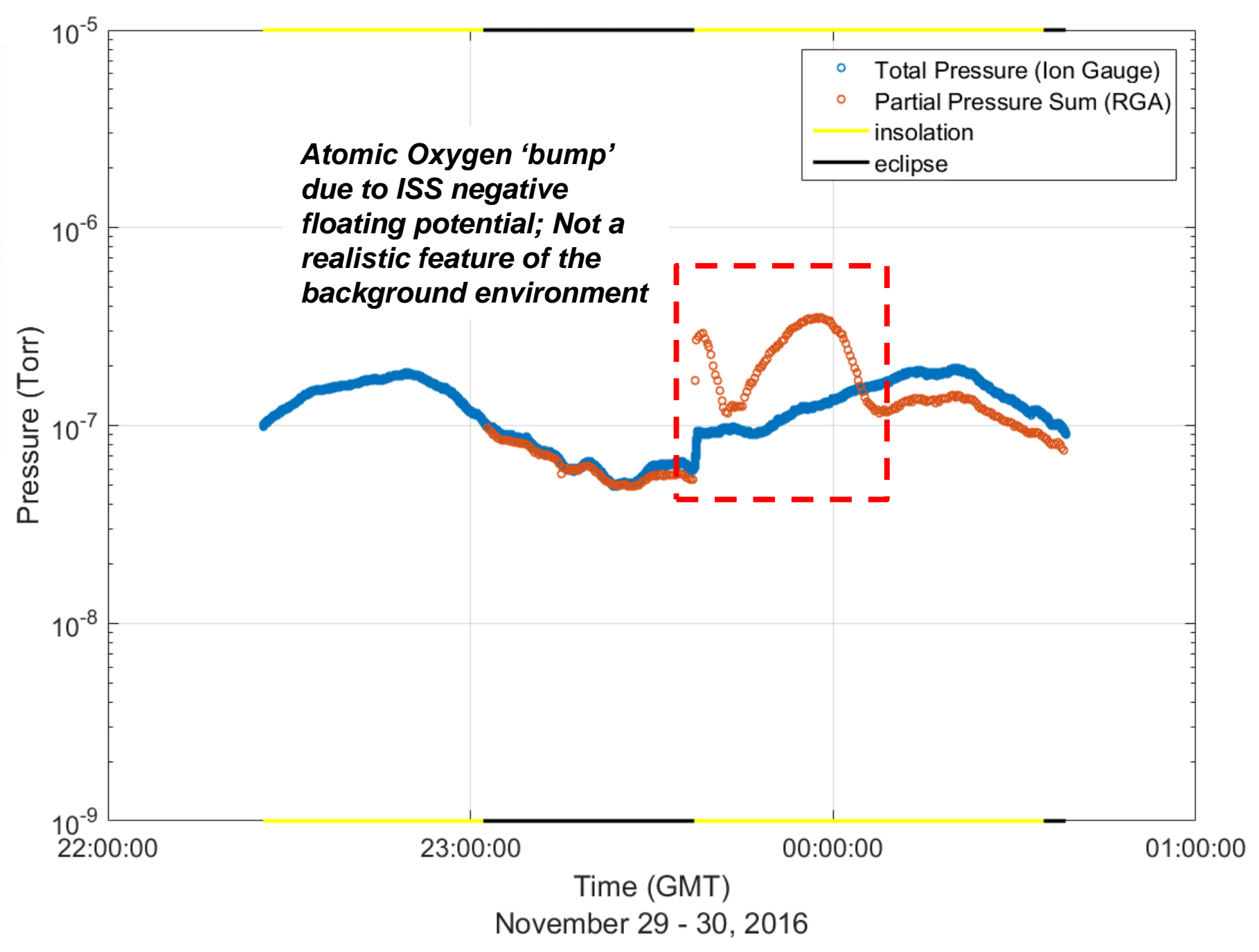

Boeing Space Environments Team 


\section{Background Scanning A: Ram (+X)}

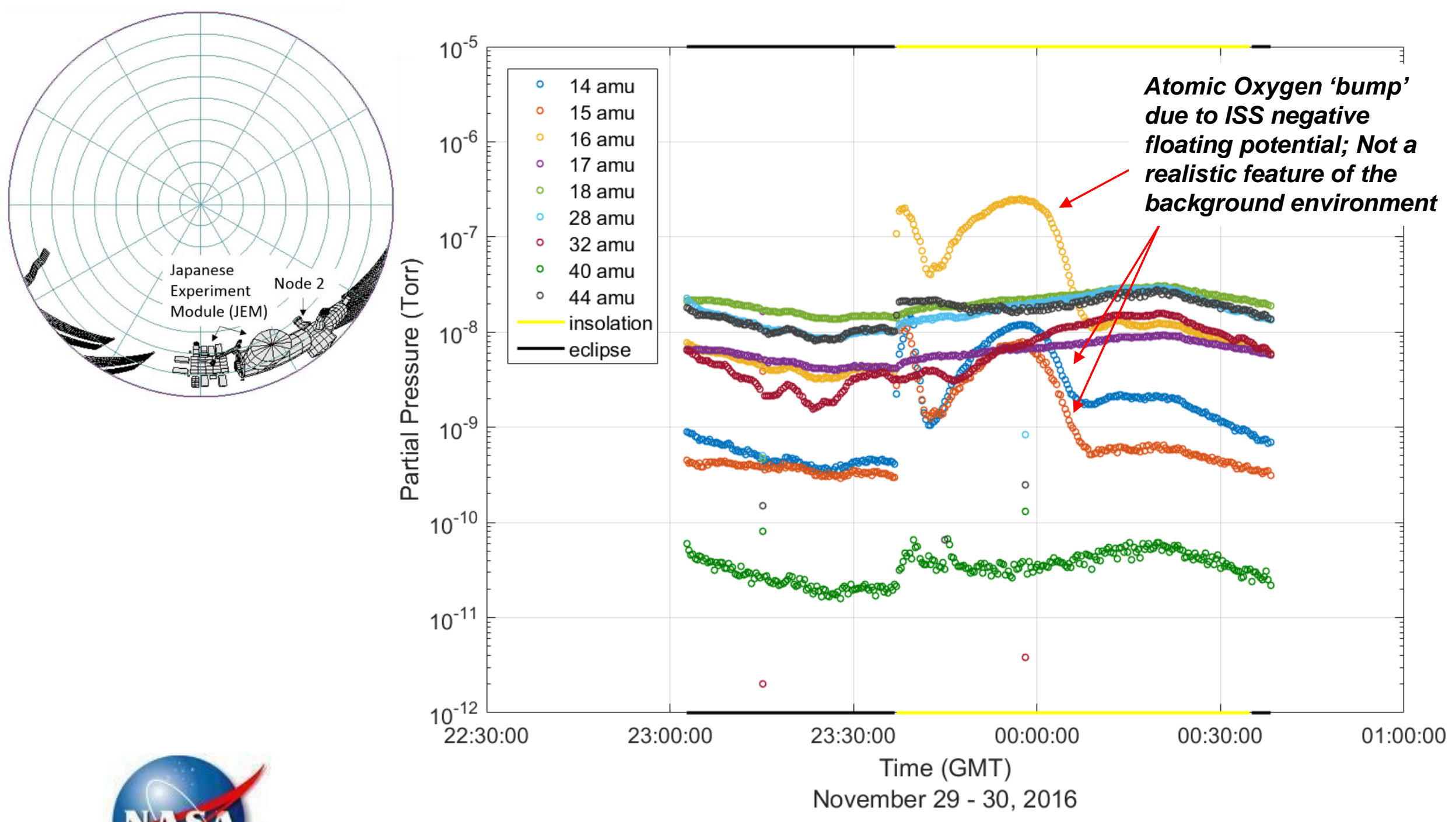

Boeing Space Environments Team 